Article

\title{
In Situ Investigation of the Adsorption of Styrene Phosphonic Acid on Cassiterite (110) Surface by Molecular Modeling
}

\author{
Guichen Gong * (D), Yuexin Han, Jie Liu *, Yimin Zhu, Yanfeng Li and Shuai Yuan \\ College of Resources and Civil Engineering, Northeastern University, Shenyang 110819, China; \\ dongdafulong@mail.neu.edu.cn (Y.H.); zhuyimin@mail.neu.edu.cn (Y.Z.); lyfeng2009@163.com (Y.L.); \\ yuanshuai_neu@163.com (S.Y.) \\ * Correspondence: neuggc@163.com (G.G.); liujie@mail.neu.edu.cn (J.L.); Tel.: +86-24-8367-6828 (G.G.)
}

Received: 28 August 2017; Accepted: 25 September 2017; Published: 27 September 2017

\begin{abstract}
The flotation, adsorption and bonding mechanisms of styrene phosphonic acid (SPA) to cassiterite were studied using microflotation tests, zeta potential measurements, solution chemistry analysis and density functional theory (DFT) calculations in this paper. Flotation results demonstrated SPA was an excellent collector for cassiterite which could recover over $85 \%$ cassiterite particles with the $\mathrm{pH}$ range $4.3-6.06$ and $40 \mathrm{mg} / \mathrm{L}$ SPA. Zeta potential measurements and solution chemistry analysis revealed the adsorption of SPA was mainly contributed by the chemisorption of the monoanions on cassiterite surfaces. Frontier molecular orbital theory analysis and adsorption energy calculation results proved the monoanion of SPA was able to replace the $\mathrm{OH}^{-}$on cassiterite surfaces. The adsorption structure optimization results confirmed the binuclear complex was the most favorable adsorption configuration of SPA on cassiterite (110) surface. Mulliken population calculations and density of states analysis indicated during the bonding process the Sn3 atom lost electrons to $\mathrm{O} 3$ atom, and the bonding interaction between $\mathrm{O} 3$ and $\mathrm{Sn} 3$ atoms was mainly from the contribution of the $2 p$ orbital of $\mathrm{O} 3$ atom and the $5 s$ and $5 p$ orbitals of Sn3 atom.
\end{abstract}

Keywords: cassiterite; styrene phosphonic acid; flotation; adsorption and bonding mechanisms; molecular modeling; density functional theory

\section{Introduction}

Flotation is an indispensable way to recover the fine cassiterite particles which are lost in gravity separation tailings [1-4]. Fatty acids were reported in the 1930s as the earliest collectors used in cassiterite flotation [5-7]. However, the selectivity of fatty acids is too poor to separate the cassiterite from gangue minerals [8]. From then on, various cassiterite flotation collectors with higher selectivity have been developed, including arsonic acids [9], phosphonic and diphosphonic acids [10,11], sulphosuccinamate [12,13], hydroxamic acids [14,15] and miscellaneous reagents [5,16,17]. Alkyl and aryl phosphonic acids have made great importance in promoting the advance of cassiterite flotation [6]. Phosphonic acids have the ability to chelate strongly with many metal ions and can be used as the extractants to recover $\mathrm{U}(\mathrm{VI}), \mathrm{Th}(\mathrm{IV}), \mathrm{Pu}(\mathrm{IV})$, and $\mathrm{Am}(\mathrm{III})$ from aqueous solutions [18]. When used in mineral processing, styrene phosphonic acid (SPA) was reported as one of the easiest to synthesize and one of the most efficient phosphonic acid cassiterite collectors [19].

Many researchers have investigated the performance of SPA in cassiterite flotation and its adsorption mechanism on cassiterite surfaces. Gruner and Bilsing [19] compared the flotation efficiency of SPA with 6 other collectors using a tin ore from Altenberg as the mineral sample; the results of both laboratory experiments and plant tests proved that only with SPA as a collector could one obtain a tin concentrate containing over $40 \%$ Sn at a high recovery simultaneously. Wottgen [20] 
examined the adsorption of phosphonic acids on cassiterite with radioactively labelled collectors and concluded that the adsorption was a chemical reaction process with the hydroxyl groups replaced by phosphonate groups. Kuys and Roberts [21] studied the adsorption of SPA on cassiterite by Fourier transform infrared attenuated total reflectance spectroscopy. They found the monoanions of SPA were the dominant species in the flotation $\mathrm{pH}$ range $3-5$, and their findings supported the conclusion proposed by Wottgen [20] that SPA adsorbed on cassiterite via ion exchange chemisorption and formed a monodentate complex, as shown in Figure 1.

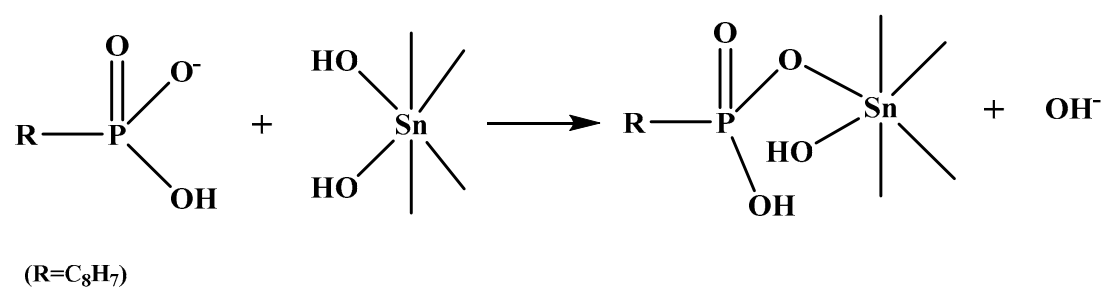

Figure 1. The ion exchange process during the adsorption of SPA on cassiterite.

Moreover, they discovered the one-point ion exchange was followed by a ring closure to form a chelate ring. According to the peaks in the spectrum, Kuys and Roberts deduced the complex formed on the mineral surface was a bidentate chelate ligand, but there was no reasonable evidence to distinguish the bidentate complex and the binuclear chelation, as shown in Figure 2.

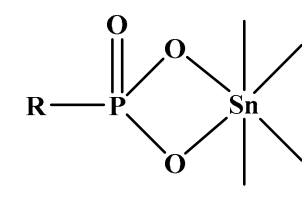

$\left(\mathrm{R}=\mathrm{C}_{8} \mathrm{H}_{7}\right)$

bidentate

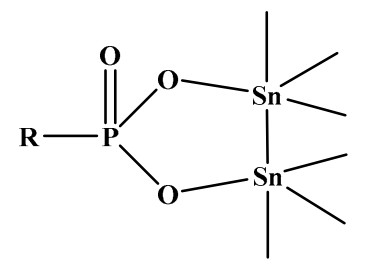

binuclear

Figure 2. The possible surface complexes formed by the adsorption of SPA on cassiterite.

Farrow and Warren [22] investigated the uptake of SPA by cassiterite by employing adsorption isotherms, zeta potential determination and the measurement of the hydroxyl ions released from the mineral surface during the uptake. The results showed that about one hydroxyl ion was released when one SPA monoanion was adsorbed. Their findings further confirmed the ion exchange happened during the chemisorption. Meanwhile, they also pointed out that there was not enough evidence to ascertain the final complex was bidentate or binuclear. However, it is clearly shown in Figure 2 that the bidentate complex results in a four-membered chelate structure, which has high strain inside itself and is thermodynamically unstable [6]. Therefore, the exact adsorption configuration of SPA on cassiterite still demands further studies [23].

One primary reason for the absence of clear evidence for the distinction between bidentate and binuclear complexes is the deficiency of in situ measurements. Fortunately, the molecular modeling technique, including density functional theory (DFT) calculations and molecular dynamics (MD) simulations, can provide an in situ way to study the adsorption of collectors on mineral surfaces at an atomic scale. Used in mineral processing, the DFT method is capable of calculating the changes of energies and charges involved in the adsorption process [24], and the MD method can predict the adsorption configurations and the possible interactions of collectors on mineral surfaces in an aqueous phase [25]. Numerous researchers have successfully investigated the stability of different $\mathrm{SnO}_{2}$ surfaces [26], the surface thermodynamic properties of $\mathrm{SnO}_{2}$ [27], the energetics and structure 
characteristics of $\mathrm{SnO}_{2}$ surfaces [28], the interaction of $\mathrm{Sb}(\mathrm{III})$ and $\mathrm{Sb}(\mathrm{V})$ ions on $\mathrm{SnO}_{2}(110)$ and $(001)$ surfaces [29] and the uptake of $\mathrm{H}_{2} \mathrm{O}$ molecules by cassiterite surfaces using the DFT method [30], as well as the static properties of the cassiterite-water interface using the MD method [31].

In this work, the flotation, adsorption and bonding processes of SPA to cassiterite were investigated by employing single mineral flotation tests, zeta potential measurements, solution chemistry calculations and density functional theory (DFT) computations. The structure-property relationship of SPA was discussed, and the most favorable adsorption conformation as well as the bonding mechanism of SPA on cassiterite surface were investigated at the atomic scale.

\section{Experimental and Computational Details}

\subsection{Minerals and Reagents}

The cassiterite mineral used in this work was gathered from Jiangxi province, China. Hand-picked high grade raw materials were crushed and dry ground in a ceramic ball mill. Thereafter, the trace amounts of ferreous minerals and calcite were removed using dilute hydrochloric acid; $\mathrm{SiO}_{2}$ was separated by a shaking table. Then, the single mineral was wet sieved and washed using distilled water; the 25-45 $\mu \mathrm{m}$ size fraction was selected for the flotation tests and the particles finer than $5 \mu \mathrm{m}$ were used in zeta potential measurements. The XRD pattern of the cassiterite particles is shown in Figure 3, and the chemical compositions of the sample are listed in Table 1 . There were no peaks for other minerals in Figure 3, implying the sample was pure enough for the subsequent experiments. The results of chemical composition analysis showed the mass content of $\mathrm{SnO}_{2}$ in the sample was $97.77 \%$.

Table 1. Chemical compositions in the single cassiterite samples (wt \%).

\begin{tabular}{ccccccccc}
\hline $\mathrm{SnO}_{2}$ & $\mathrm{SiO}_{2}$ & $\mathrm{CaCO}_{3}$ & $\mathrm{MgO}$ & $\mathrm{Al}_{2} \mathrm{O}_{3}$ & $\mathrm{TFe}$ & $\mathrm{Pb}$ & $\mathrm{Zn}$ & $\mathrm{Cu}$ \\
\hline 97.77 & $<0.001$ & $<0.001$ & 0.075 & $<0.01$ & 0.007 & $<0.001$ & 0.0027 & $<0.001$ \\
\hline
\end{tabular}

Styrene phosphonic acid with a purity $94 \%$ was used as the collector, which was bought from a commercial company and was purified by recrystallization. The frother $2 \#$ oil was obtained from a concentrator in Jiangxi province, China. The analytical grade $\mathrm{pH}$ modifiers $\mathrm{HCl}$ and $\mathrm{NaOH}$ were prepared as $0.1 \mathrm{~mol} / \mathrm{L}$ solutions. All the experiments were performed using distilled water.

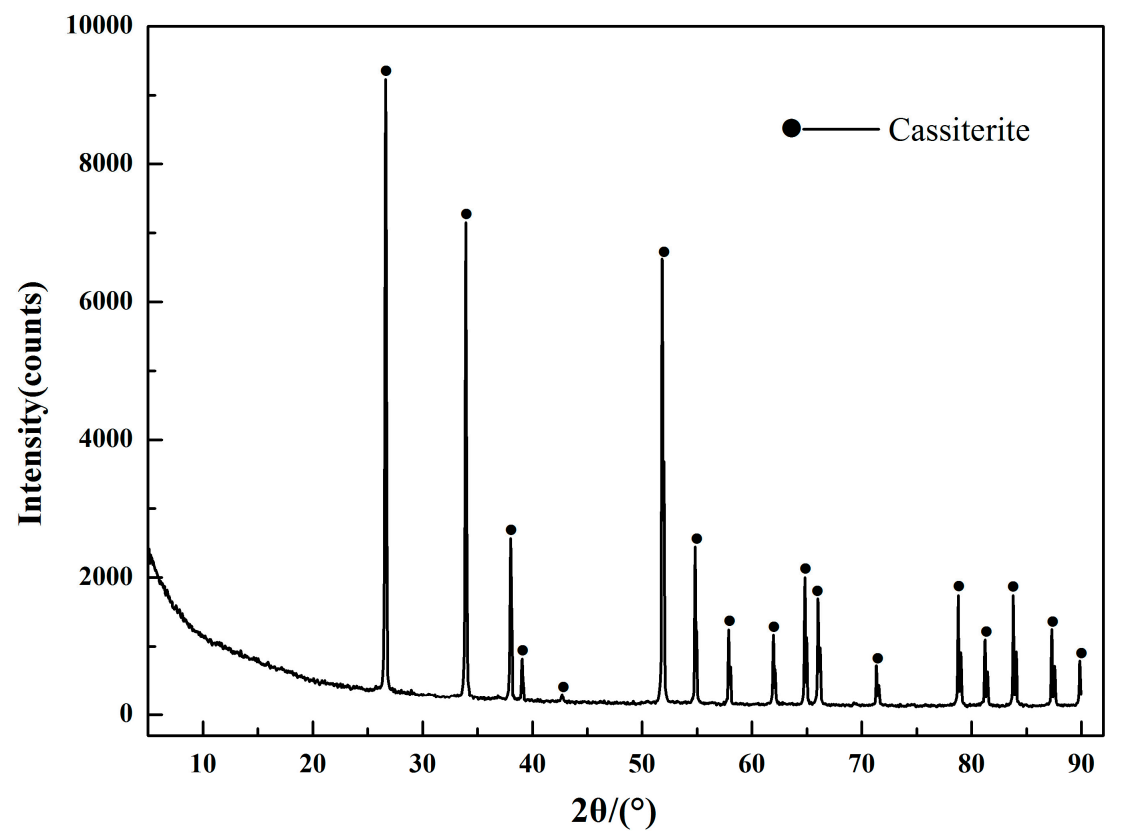

Figure 3. XRD pattern of cassiterite. 


\subsection{Flotation Tests}

Single mineral flotation tests were conducted on a XFG laboratory flotation machine with a $30 \mathrm{~mL}$ cell. The agitation speed was kept at $1992 \mathrm{r} / \mathrm{min}$ all the time. Every test used $2 \mathrm{~g}$ cassiterite sample and $20 \mathrm{~mL}$ distilled water. The suspensions would be stirred for $3 \mathrm{~min}$, and then the $\mathrm{pH}$ was regulated to the desired values using $\mathrm{HCl}$ or $\mathrm{NaOH}$ solutions; after another 3 min stirring, the predetermined amount of SPA was added and agitated for $5 \mathrm{~min}$, and then $100 \mathrm{mg} / \mathrm{L}$ 2\# oil was used. The flotation lasted for $5 \mathrm{~min}$; the collected products and tailings were dried and weighed separately. Each test was repeated 3 times under the same conditions, and the average recoveries were reported in this paper.

\subsection{Zeta Potential Measurements}

A Malvern Nano-ZS90 zeta potential analyzer was used to measure the zeta potentials. A $1 \times 10^{-3} \mathrm{~mol} / \mathrm{L} \mathrm{KCl}$ solution was used as the background electrolyte. The suspension contained $20 \mathrm{mg}$ cassiterite particles finer than $5 \mu \mathrm{m}$ and $50 \mathrm{~mL}$ deionized water and was agitated by a magnetic stirrer. After adding the predetermined concentration of SPA, the $\mathrm{pH}$ was adjusted to the desired value using $\mathrm{HCl}$ or $\mathrm{NaOH}$ solutions and then the suspension was allowed to settle for $10 \mathrm{~min}$. The supernatant was taken for the measurements and every measurement was repeated at least 3 times to generate an average value. The measurements were performed at $298 \mathrm{~K}$ with a maximum deviation of $\pm 2.0 \mathrm{mV}$.

\subsection{Computational Details}

All the molecular modeling functions were performed using the Cambridge serial total energy package (CASTEP) and $\mathrm{DMol}^{3}$ modules in Materials Studio 6.0 (MS). The frontier molecular orbital (FMO) eigenvalues of adsorbate species were calculated using the $\mathrm{DMol}^{3}$ module. The geometry optimization and energy calculation of mineral structures, adsorbate species and substrate-adsorbate complexes were performed in CASTEP modules.

A generalized gradient approximation exchange correlation functional that was developed by Wu-Cohen (WC) [32] was used for all the computations. The calculations were conducted in reciprocal space, the plane wave cutoff energy was $580 \mathrm{eV}$ and the $k$-point sampling separation was kept $0.071 / \AA$ throughout the whole computation. The pseudo potential was ultrasoft and the convergence criteria were set as follows: the energy tolerance, $2 \times 10^{-5} \mathrm{eV} /$ atom; the maximum force tolerance, $0.05 \mathrm{eV} / \AA$; the maximum displacement tolerance, $0.002 \AA$; the maximum stress tolerance, $0.1 \mathrm{GPa}$ and the SCF tolerance $1 \times 10^{-6} \mathrm{eV} /$ atom. All the adsorbate species were created and geometry optimized in a $20 \times 20 \times 40 \AA^{3}$ periodic cell, and the $k$-point set was restricted to gamma point.

When an adsorbate adsorbs on a mineral surface in molecular modeling, the interaction energy is calculated using the following expression:

$$
\mathrm{E}_{\mathrm{ads}}=\mathrm{E}_{\text {complex }}-\mathrm{E}_{\text {surface }}-\mathrm{E}_{\text {adsorbate }}
$$

where the $\mathrm{E}_{\mathrm{ads}}$ is the adsorption energy, $\mathrm{E}_{\text {complex }}$ refers to the total energy of the complex formed by the adsorbing of different species on cassiterite surface slab structures, and $E_{\text {surface }}$ and $E_{\text {adsorbate }}$ are the total energy of the surface slab structures and the adsorbate species respectively. Attention needs to be paid to the following: the theoretically computational adsorption energy is not the real energy change in a chemical reaction process, but it can be a good measure of the adsorption strength of different adsorbate species on a mineral surface [33]. A negative adsorption energy means the interaction of the adsorbate species on the mineral surface is spontaneous and a more negative value means the adsorption is more favorable [34]. 


\section{Results and Discussion}

\subsection{Single Mineral Flotation Tests}

The influences of $\mathrm{pH}$ values on the recovery of cassiterite with SPA $(100 \mathrm{mg} / \mathrm{L})$ as the collector are depicted in Figure $4 \mathrm{a}$. The recovery of cassiterite remained above $85 \%$ in the $\mathrm{pH}$ range $4.3-6.06$. When the $\mathrm{pH}$ value was around 4.3, the recovery of cassiterite reached a peak value $88.56 \%$, which agreed well with the $\mathrm{pH}$ value 4.5 [21] used in industrial practice. However, once the $\mathrm{pH}$ values of the solutions entered the alkaline region, the recovery of cassiterite decreased rapidly. When the $\mathrm{pH}$ value was 10.54 , the recovery was only $14.29 \%$. The results in Figure $4 \mathrm{a}$ are accordant with the data published in prior papers $[23,35]$ and demonstrated the $\mathrm{pH}$ values had a great influence on the flotation behavior of cassiterite; the appropriate $\mathrm{pH}$ range for the flotation of cassiterite using SPA as a collector was 4.3-6.06.
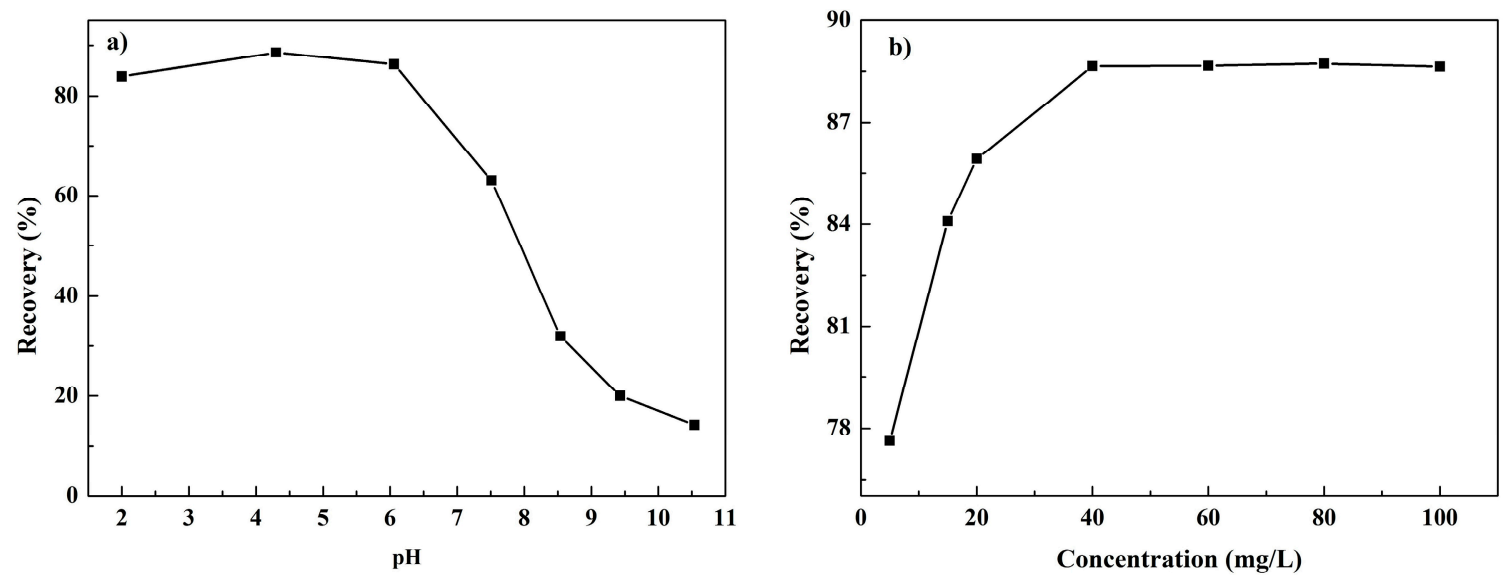

Figure 4. The flotation recoveries of cassiterite as functions of $\mathrm{pH}(\mathbf{a})$ and the concentration of SPA (b).

Flotation test results of the effects of the concentration of SPA on the recovery of cassiterite at $\mathrm{pH} 4.3 \pm 0.1$ are plotted in Figure $4 \mathrm{~b}$. When the dosage was increased from $5 \mathrm{mg} / \mathrm{L}$ to $40 \mathrm{mg} / \mathrm{L}$, the recovery climbed from $77.63 \%$ to $88.65 \%$ accordingly, whereafter no obvious change was observed in the recovery of cassiterite with the increase of the concentration of SPA and was maintained at around $88.6 \%$. The optimal SPA concentration for the flotation of cassiterite single mineral was $40 \mathrm{mg} / \mathrm{L}$.

\subsection{Zeta Potential Measurements and Solution Chemistry Analysis}

In the mineral processing field, zeta potential measurements are being widely used to speculate the possible adsorption mechanism of reagents on mineral surfaces by unscrambling the surface potentials before and after the adsorption, and the solution chemistry analysis can be used to find the main functional reagent species [36]. The zeta potentials of cassiterite in aqueous surroundings with the absence and presence of SPA, the relative contents of the species of SPA and recovery of cassiterite as a function of $\mathrm{pH}$ values are shown in Figure 5.

As shown in Figure 5a, the measured isoelectric point (IEP) of pure cassiterite surfaces was 3.8; this value was similar to the results reported in the literature $[24,35]$. Cassiterite surfaces were positively charged when $\mathrm{pH}<3.8$, and when the $\mathrm{pH}$ value exceeded 3.8 , the surface charge values turned negative. Cassiterite is an oxide mineral and its potential determining ions are hydrogen and hydroxide ions. The negative charge when $\mathrm{pH}>3.8$ could be considered as a result of the adsorption of many hydroxide ions on cassiterite. After treatment with SPA, the zeta potentials decreased in the pH range 2.9-8.5 and the IEP shifted to 3.1; these changes implied some species of SPA were adsorbed by the cassiterite surfaces, and the flotation of cassiterite also mainly took place in this $\mathrm{pH}$ region. 
However, Figure $5 \mathrm{~b}$ showed the dominating species in the $\mathrm{pH}$ region 2.9-8.5 were monoanions and dianions of SPA, both of which were negatively charged. Therefore, the uptake of these anion species by the negatively charged cassiterite surface must had overcome the electrostatic repulsion, indicating a chemisorption with ion exchange rather than electrostatic attraction had taken place.
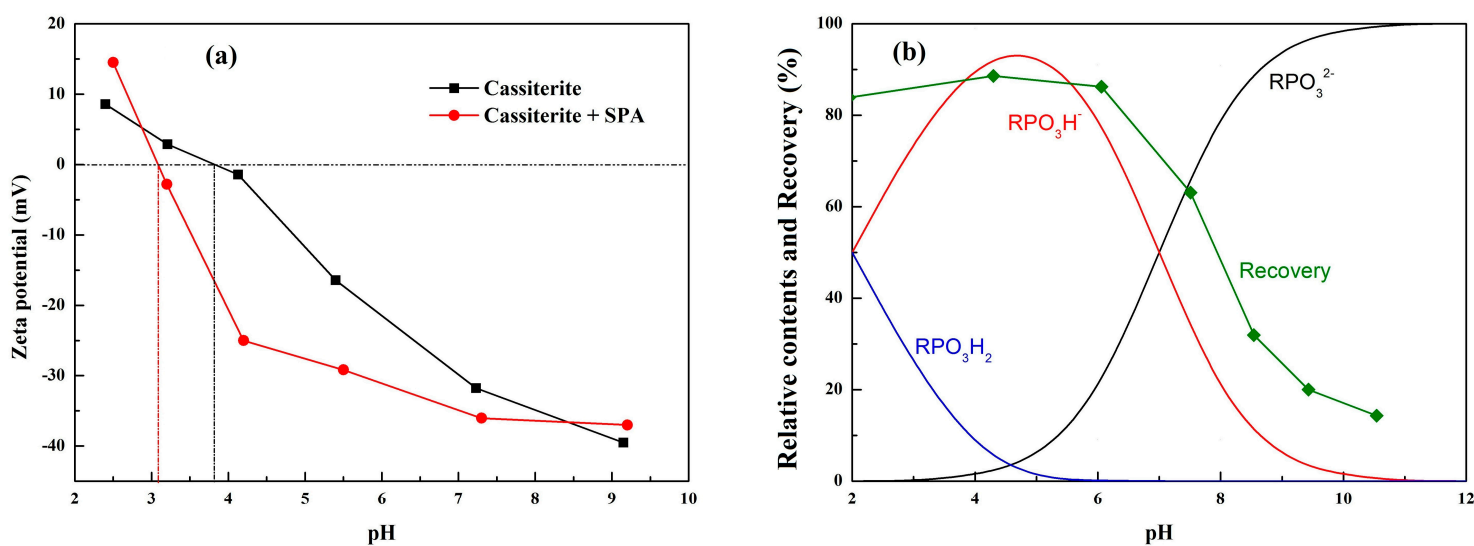

Figure 5. Zeta potentials of cassiterite in the absence and presence of SPA $40 \mathrm{mg} / \mathrm{L}$ (a), relative contents of the species of SPA and recovery of cassiterite $(\mathbf{b})$ as a function of $\mathrm{pH}$ values.

According to the reported dissociation constants of SPA, i.e., $\mathrm{pK}_{\mathrm{a} 1}=2.0$ and $\mathrm{pK}_{\mathrm{a} 1}=7.0$ [22], the relative amounts of different species of SPA in the solution as a function $\mathrm{pH}$ values were calculated and are plotted in Figure $5 b$. The trend of the curve of the recovery in Figure $5 b$ is very similar to that of the SPA monoanions distribution curve. In $\mathrm{pH}$ range 2-4.3, the recovery of cassiterite increased with the increase in monoanions. In $\mathrm{pH}$ range $4-6$, the distribution frequency of SPA monoanions was over $80 \%$, and the recovery retained an almost equilibrium value of $88 \%$. When the $\mathrm{pH}$ entered the alkaline range, the content of monoanions descended rapidly and the recovery of cassiterite worsened too. In basic areas, the surface charge of cassiterite kept decreasing, and the dominating dianion species held more negative charges as well, causing a much more intense electrostatic repulsive force. Therefore, the dianions were not able to adsorb directly and the recovery of cassiterite decreased with the increase in dianions. The similarity of the trends between the recovery of cassiterite and the distribution of SPA monoanions could be interpreted as follows: the monoanions were the functional species that adsorbed on cassiterite surfaces during flotation.

\subsection{Structure Details and Mulliken Populations of SPA Species}

The structure of the SPA molecule and the numbering scheme are shown in Figure 6. The specific structure details and Mulliken populations are listed in Table 2.

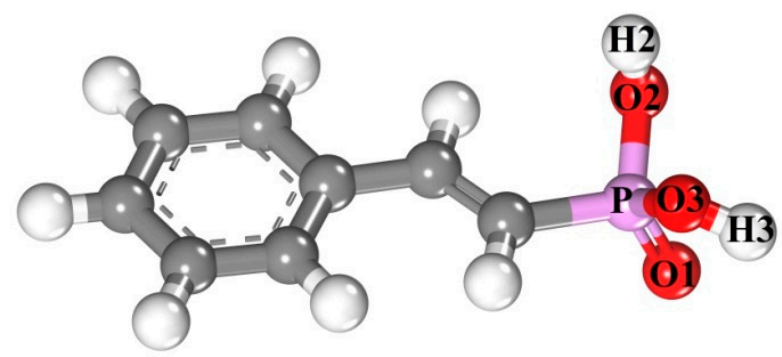

Figure 6. The structure of the SPA molecule and the numbering scheme (colour codes: Gray-C, White-H, Red-O, Purple-phosphorus). 
Table 2. Structure details and Mulliken populations of SPA species.

\begin{tabular}{ccccccccccc}
\hline \multirow{2}{*}{ Species } & \multicolumn{3}{c}{ Bond Lengths/Å } & \multicolumn{3}{c}{ Bond Angles/ $^{\circ}$} & \multicolumn{3}{c}{ Mulliken Charges } \\
\cline { 2 - 11 } & $\mathbf{P}=\mathbf{O 1}$ & $\mathbf{P - O 2}$ & $\mathbf{P}-\mathbf{O} 3$ & O1-P-O2 & O2-P-O3 & O1-P-O3 & P & O1 & O2 & O3 \\
\hline Molecular & 1.456 & 1.590 & 1.595 & 111.614 & 104.880 & 114.671 & 2.230 & -1.040 & -1.020 & -1.030 \\
Monoanion & 1.493 & 1.600 & 1.487 & 110.643 & 109.927 & 117.591 & 2.320 & -0.900 & -1.030 & -0.960 \\
Dianion & 1.510 & 1.503 & 1.507 & 111.747 & 113.658 & 110.868 & 2.410 & -0.810 & -0.870 & -0.860 \\
\hline
\end{tabular}

In the molecular form, the bond lengths of $\mathrm{O} 2-\mathrm{H} 2$ and $\mathrm{O} 3-\mathrm{H} 3$ were 0.980 and 0.981 , respectively; thus, the $\mathrm{O} 3-\mathrm{H} 3$ bond was broken during the first dissociation. It was noticed that the length of $\mathrm{P}=\mathrm{O} 1$ increased after each dissociation stage, from $1.456 \AA$ to $1.493 \AA$ and to $1.510 \AA$. Compared to the molecular form, the corresponding $\mathrm{P}-\mathrm{O}$ bonds were shorter in the anion forms. However, the differences between the lengths of the $\mathrm{P}=\mathrm{O} 1$ bond and $\mathrm{P}-\mathrm{O}$ bonds decreased after the dissociations. In dianion form, the lengths of the three bonds were similar, namely, $1.510 \AA, 1.503 \AA$ and $1.507 \AA$. These changes could be attributed to the following: after the dissociations, the $p$ electrons of the three $\mathrm{O}$ atoms formed a large conjugative $\pi$ bond. As for the bond angles, the $\mathrm{O} 1-\mathrm{P}-\mathrm{O} 2$ bond angle underwent relatively little change in the dissociations, whereas the $\mathrm{O} 2-\mathrm{P}-\mathrm{O} 3$ bond angle increased after each dissociation stage. Similarly, the diversities between the three bond angles decreased.

The Mulliken charges of the relevant atoms in the phosphate group are shown in Table 2 . The charge values implied the $\mathrm{O}$ atoms were negatively charged and were rich in electrons. Therefore, the $\mathrm{O}$ atoms had high electron-donating ability and would be the solid-affinitive center during the adsorption process, implying bonds can be generated between the $\mathrm{O}$ atoms and the $\mathrm{Sn}$ atoms on the mineral surface.

\subsection{Frontier Molecular Orbital Theory Analysis}

Based on the FMO theory which was proposed in 1952 by Fukui Kenichi, the reactivity of a reactant can be described by the separation between the highest occupied molecular orbital (HOMO) and the lowest unoccupied molecular orbital (LUMO), namely, $\mathrm{E}_{\mathrm{LUMO}}$-HOMO. A previous study pointed out there exists an inverse relationship between the interaction energy and the frontier orbital energy separation [37]: a narrower frontier orbital energy separation value indicates a larger interaction energy, implying the interaction is more favorable. When the adsorbates are adsorbed by the mineral surfaces, the HOMO of the adsorbates offer electrons to the LUMO of the minerals and become bonded. On the other hand, the LUMO of the adsorbates can also take in the electrons supplied by the HOMO of the mineral surface atoms to generate back donation bonds [38]. Therefore, the frontier orbital energy separations can be used to measure the activities and the possible interaction strengths of different adsorbates on cassiterite surface.

The frontier orbital energy separations of SPA species, $\mathrm{H}_{2} \mathrm{O}$ molecular and $\mathrm{OH}^{-}$ion were calculated and are given in Table 3.

Table 3. The frontier orbital energy separations of different adsorbates $\left(\mathrm{R}=\mathrm{C}_{8} \mathrm{H}_{7}\right)$.

\begin{tabular}{cccccc}
\hline Adsorbates & $\mathbf{R P O}_{3} \mathbf{H}_{\mathbf{2}}$ & $\mathbf{R P O}_{3} \mathbf{H}^{-}$ & $\mathbf{R P O}_{3}{ }^{2-}$ & $\mathbf{H}_{\mathbf{2}} \mathbf{O}$ & $\mathbf{O H}^{-}$ \\
\hline $\mathrm{E}_{\text {LUMO-HOMO }}(\mathrm{eV})$ & 3.389 & 0.448 & 0.624 & 7.647 & 7.717 \\
\hline
\end{tabular}

Table 3 shows the $\mathrm{E}_{\mathrm{LUMO}} \mathrm{HOMO}$ of the adsorbates sorted in ascending order as follows: $\mathrm{RPO}_{3} \mathrm{H}^{-}<$ $\mathrm{RPO}_{3}{ }^{2-}<\mathrm{RPO}_{3} \mathrm{H}_{2}<\mathrm{H}_{2} \mathrm{O}<\mathrm{OH}^{-}$. The anions of SPA held much smaller frontier orbital energy separations than the moleculars, indicating the anions were activated during the dissociations. The monoanion of SPA had the narrowest energy separation, indicating its reactivity was the highest, which was in good agreement with the experimental fact that the recovery reached a peak value when the monoanions dominated the species. Nevertheless, the energy separation of $\mathrm{RPO}_{3}{ }^{2-}$ was extremely close to that of $\mathrm{RPO}_{3} \mathrm{H}^{-}$while its flotation behavior to cassiterite was poor, which was probably because the electrostatic repulsion was too strong for the dianions to overcome in a basic $\mathrm{pH}$ 
range. Besides, the frontier of $\mathrm{OH}^{-}$was much greater than that of the monoanion of SPA, implying its activity was lower and could be replaced on cassiterite surfaces by the latter.

\subsection{Adsorption Configurations of SPA on Cassiterite}

In the published papers, it has been well proved that the (110) surface is the most stable and expressed plane of cassiterite crystal $[28,29]$ and here the (110) surface slab is used as the adsorption substrate. The (110) surface slab containing 7 layers of atoms and $20 \AA$ vacuum depth was cleaved from a geometry optimized cassiterite unit-cell. The optimized adsorbate species were docked on the surfaces with the consideration of feasible interactions between the $\mathrm{O}$ atoms and the surface $\mathrm{Sn}$ atoms. Various initial adsorption models were created and optimized, and the ones possessing the minimum interaction energies were reported in this work.

According to previous studies and the results mentioned above, the one-point ion exchange chemisorption was confirmed as the first step. Kuys and Roberts [21] speculated the adsorption of SPA on cassiterite resulted in a four-membered chelate ring based on their FTIR spectra. However, four-membered chelate rings are thermodynamically unstable [6]. In this paper, the monodentate, bidentate and binuclear complexes were created and optimized using CASTEP to confirm the most favorable adsorption configuration of SPA on the cassiterite (110) surface. The initial and optimized adsorption conformations are shown in Figure 7.

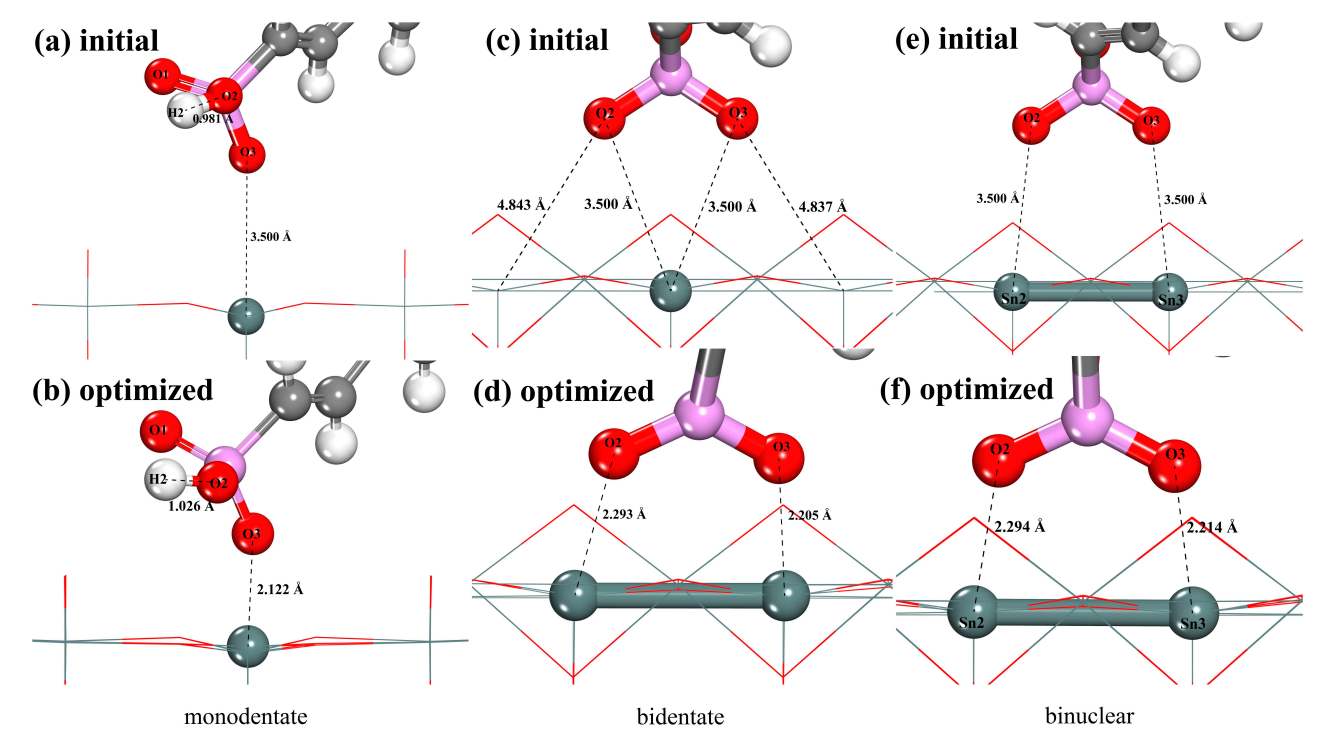

Figure 7. The initial and optimized monodentate, bidentate and binuclear adsorption conformations (colour codes: Light gray-C, White- $\mathrm{H}$, Red—O, Purple—phosphorus, Dark gray—Sn).

It could be seen in the monodentate complex, after the adsorption, the bond length of $\mathrm{O} 2-\mathrm{H} 2$ increased from $0.981 \AA$ to $1.026 \AA$, implying the remaining proton $\mathrm{H} 2$ became more acidic and tended to dissociate. This change favored the possibility that the ring closure would take place after the one-point adsorption. The original bidentate complex is shown in Figure 7c; the two ionized $\mathrm{O}$ atoms were docked above one surface $\mathrm{Sn}$ atom. As the computation steps were ongoing, the two $\mathrm{O}$ atoms synchronously approached the $\mathrm{Sn}$ atom. However, when the distances between the $\mathrm{O}$ atoms and the Sn atom were short enough, the four-membered ring experienced larger and larger internal tension. Finally, the balance was broken and the $\mathrm{O} 2$ atom was forced to get close to an adjacent Sn atom and bonded with it. An amazing finding was the adsorption configurations obtained by optimizing the initial bidentate and binuclear complexes were almost identical to each other and formed a five-membered chelate ring. These results intuitively demonstrated the four-membered ring could not exist stably. The bidentate complex could be an intermediate product during the adsorption of SPA on cassiterite, but the binuclear complex was the ultimate adsorption configuration. 
The adsorption energies of the monodentate, bidentate and binuclear complexes and the adsorption of $\mathrm{H}_{2} \mathrm{O}$ and $\mathrm{OH}^{-}$on cassiterite (110) surfaces are given in Table 4. The results in Table 4 showed the adsorption energies of $\mathrm{H}_{2} \mathrm{O}$ and $\mathrm{OH}^{-}$on $\mathrm{SnO}_{2}$ (110) surface were $-76.74 \mathrm{~kJ} / \mathrm{mol}$ and $-115.22 \mathrm{~kJ} / \mathrm{mol}$ respectively, demonstrating the $\mathrm{H}_{2} \mathrm{O}$ and $\mathrm{OH}^{-}$could easily and spontaneously be adsorbed on the surface. This finding was consistent with the results of the flotation tests and the zeta potential measurements, i.e., that the native floatability of cassiterite was poor and the surface charge was negative in a wide $\mathrm{pH}$ range. The adsorption energy of the monodentate complex was $-201.06 \mathrm{~kJ} / \mathrm{mol}$ and was more negative than that of the $\mathrm{OH}^{-}$, signifying the monoanion of SPA had a stronger affinity for cassiterite and was able to displace the $\mathrm{OH}^{-}$. The adsorption energies of the optimized bidentate and binuclear complexes were extremely close to each other, which were $-363.24 \mathrm{~kJ} / \mathrm{mol}$ and $-369.52 \mathrm{~kJ} / \mathrm{mol}$, respectively. Combining the results in Figure 7 and Table 4, it could be found the bidentate and binuclear complexes ultimately resulted in a five-membered ring, and the energy changes were much the same. Therefore, the binuclear complex could be confirmed as the final adsorption configuration of SPA on the cassiterite (110) surface. The possible adsorption process is delineated in Figure 8.

Table 4. The interaction energies of different adsorption complexes on the cassiterite (110) plane.

\begin{tabular}{cccccc}
\hline Adsorption Complex & $\mathbf{H}_{\mathbf{2}} \mathbf{O}$ & $\mathbf{O H}^{-}$ & Monodentate & Bidentate & Binuclear \\
\hline Interaction energy, $\mathrm{kJ} / \mathrm{mol}$ & -76.74 & -115.22 & -201.06 & -363.24 & -369.52 \\
\hline
\end{tabular}

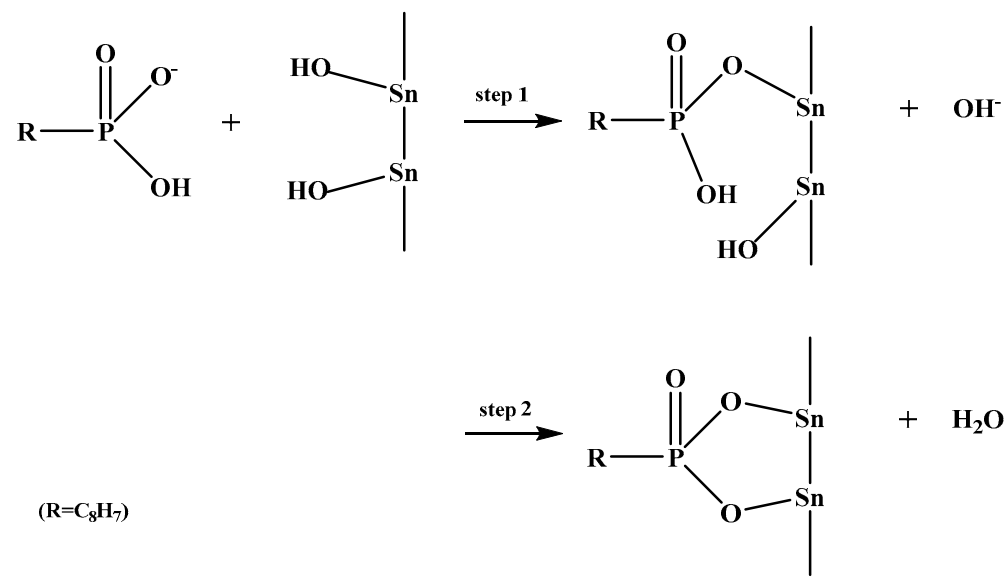

Figure 8. The speculated adsorption process of SPA on the cassiterite surface.

\subsection{Bonding Mechanism between SPA and the Cassiterite (110) Surface}

The bonding mechanism of SPA on cassiterite was discussed in detail in this paper by analyzing the Mulliken populations and the density of states of the Sn3-O3 bond as shown in Figure 7f. Mulliken population analysis is a useful tool to explore the electron transfer during a chemical reaction [24]. The Mulliken populations of Sn3 and O3 atoms before and after the adsorption are listed in Table 5; negative charge values indicate the atom obtained electrons from others.

Table 5. Mulliken populations of Sn3 and $\mathrm{O} 3$ atoms before and after the adsorption.

\begin{tabular}{cccccc}
\hline Atom & Status & $s$ & $p$ & Total & Charge/e \\
\hline \multirow{2}{*}{ Sn3 } & Before adsorption & 1.00 & 1.20 & 2.20 & 1.80 \\
& After adsorption & 0.93 & 1.22 & 2.15 & 1.85 \\
\hline \multirow{2}{*}{ O3 } & Before adsorption & 1.92 & 4.94 & 6.86 & -0.86 \\
& After adsorption & 1.88 & 5.07 & 6.95 & -0.95 \\
\hline
\end{tabular}


The results in Table 5 showed that for both Sn3 and $\mathrm{O} 3$ atoms, after the adsorption, the electrons in $s$ orbitals decreased and the electrons in $p$ orbitals increased. This could be a result from when the $\mathrm{Sn} 3$ and $\mathrm{O} 3$ atoms were close to each other, the inner shell $s$ orbital valence electrons were attracted by the foreign nucleuses and jumped to higher energy levels. Furthermore, the total Mulliken population of the Sn3 atom decreased from 2.20 to 2.15 and that of the $\mathrm{O} 3$ atom increased from 6.86 to 6.95 , and the charge of the $\mathrm{Sn} 3$ atom increased from 1.80 to 1.85 and that of the $\mathrm{O} 3$ atom decreased from -0.86 to -0.95 , implying the $\mathrm{O} 3$ atom acquired electrons from $\mathrm{Sn} 3$ atom in the bonding process.

Further insight into the bonding mechanism of the binuclear complex was performed by comparing the density of states (DOS) before and after the adsorption. Density of states analysis is an interpretational tool for understanding the reactivity and the bonding mechanism in a surfaceadsorbate interaction [39]. The density of states of Sn3 and O3 atoms before and after the adsorption is shown in Figure 9.
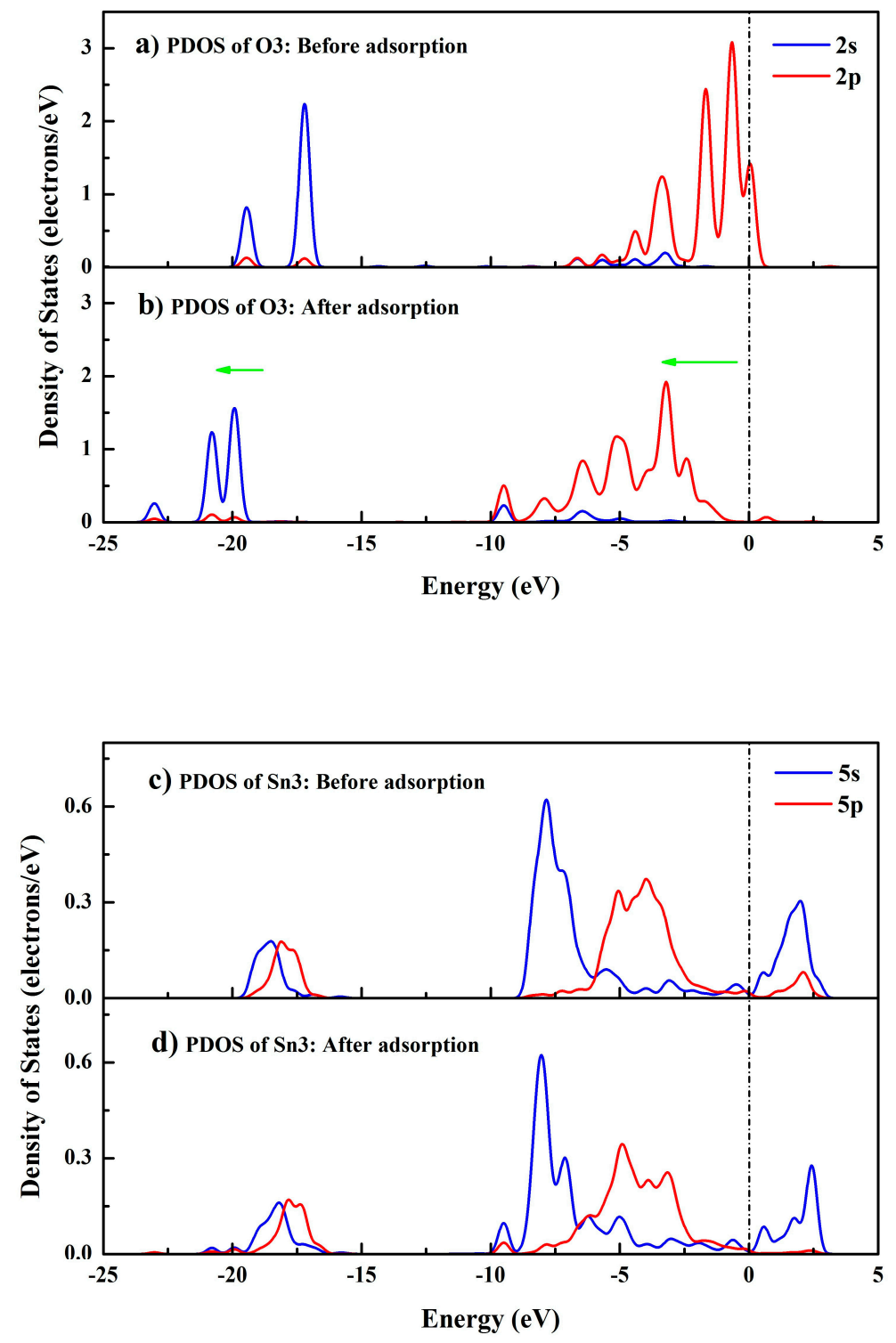

Figure 9. Cont. 


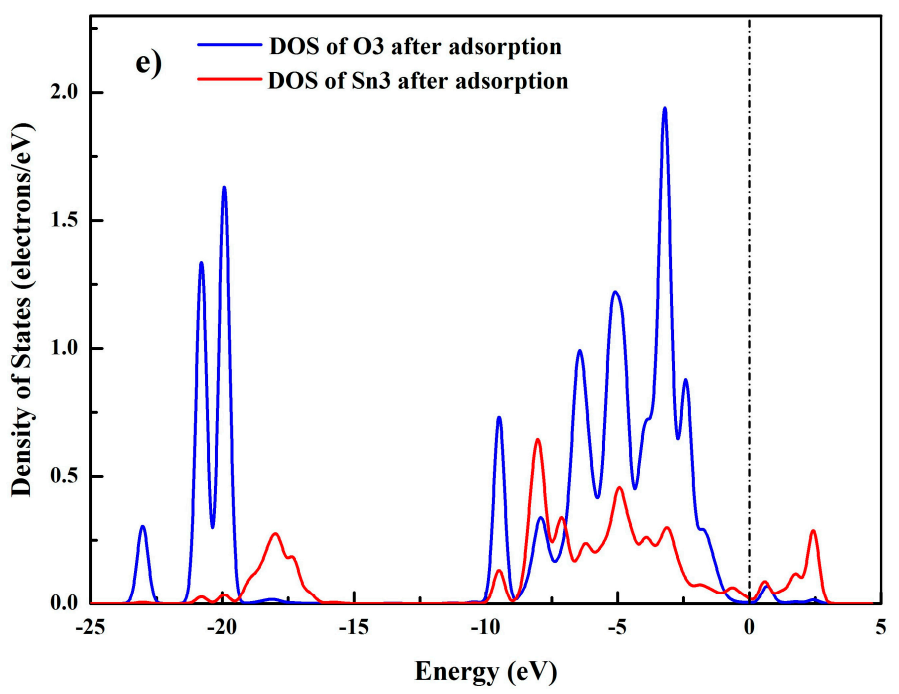

Figure 9. Density of states of $\mathrm{O} 3$ and $\mathrm{Sn} 3$ atoms before and after the adsorption (the green arrows indicate the shift direction of the peaks).

Figure 9a shows that before the adsorption, the $2 p$ orbital of $\mathrm{O} 3$ atom dominated the peaks around the Fermi level, and part of the $2 p$ orbital crossed the Fermi level, implying the $\mathrm{O} 3$ atom was excited and the activity was mainly contributed from the $2 p$ orbital. For the $\mathrm{Sn} 3$ atom, before the adsorption, the $5 s$ and $5 p$ orbitals dominated the peaks near the Fermi level as shown in Figure 9c, and parts of the $5 s$ and $5 p$ orbital also appeared in the conduction band, indicating the $\mathrm{Sn} 3$ atom was also activated before the adsorption. In Figure 9b, after the interaction, the peak at the Fermi level of the states of the O3 atom disappeared, and all the peaks delocalized and shifted toward lower energy compared with Figure $9 \mathrm{a}$. Moreover, the intensities of the states in Figure $9 \mathrm{~b}$ decreased. In Figure $9 \mathrm{~d}$, after the adsorption, the states contributed from the $5 p$ orbital of $\mathrm{Sn} 3$ in the conduction band disappeared, and the delocalization of the peaks increased. These changes in the density of states of the $\mathrm{O} 3$ and $\mathrm{Sn} 3$ atoms demonstrated that after the bonding process, the $\mathrm{O} 3$ and $\mathrm{Sn} 3$ atoms were stabilized. Meanwhile, Figure 9e revealed that after the adsorption, the states of the $\mathrm{O} 3$ and $\mathrm{Sn} 3$ atoms showed strong hybridization in the energy range $-10 \mathrm{eV}$ to $0 \mathrm{eV}$. Combining Figure $9 \mathrm{~b}, \mathrm{~d}, \mathrm{e}$, it was found that the hybridization was mainly between the $2 p$ orbital of the $\mathrm{O} 3$ atom and the $5 s$ and $5 p$ orbitals of the $\mathrm{Sn} 3$ atom, demonstrating the Sn3-O3 bond was mainly contributed by the electrons in the $2 p$ orbital of the O3 atom and the $5 s$ and $5 p$ orbitals of the $\mathrm{Sn} 3$ atom.

\section{Conclusions}

The flotation, adsorption and bonding mechanisms of SPA to cassiterite were investigated in this paper by adopting flotation tests, zeta potential measurements, solution chemistry analysis and density functional calculations. Flotation tests results demonstrated that SPA was an excellent collector for cassiterite and could recover more than $85 \%$ cassiterite particles at the $\mathrm{pH}$ range $4.3-6.06$ and an optimal concentration of $40 \mathrm{mg} / \mathrm{L}$. Zeta potential measurements and solution chemistry analysis revealed the adsorption of SPA was a chemisorption of the monoanions of SPA on cassiterite surfaces. The results of the adsorption configuration optimizations confirmed the binuclear complex was the final adsorption structure of SPA on the cassiterite (110) surface. The adsorption energy of the monoanion of SPA on cassiterite was more negative than that of the $\mathrm{OH}^{-}$, and this finding supported the ion exchange chemisorption theory proposed in previous literature. Mulliken population calculations and density of states analysis indicated that during the bonding process, the $\mathrm{Sn} 3$ atom lost electrons to the $\mathrm{O} 3$ atom, and the Sn3-O3 bond was formed mainly by the contributions of the $2 p$ orbital of the $\mathrm{O} 3$ atom and the $5 s$ and $5 p$ orbitals of the Sn 3 atom. The results of the experiments and the computational analysis agreed well with each other. 
Acknowledgments: The authors are greatly thankful for and appreciate the financial support from the National Natural Science Foundation of China (Grant number 51674066, 51204035, 51474055).

Author Contributions: Guichen Gong and Yuexin Han conceived and designed the experiments; Guichen Gong performed the experiments; Guichen Gong and Jie Liu analyzed the data; Yinmin Zhu, Yanfeng Li and Shuai Yuan contributed reagents/materials/analysis tools; Guichen Gong wrote the paper.

Conflicts of Interest: The authors declare no conflict of interest.

\section{References}

1. Sreevinas, T.; Manohar, C. Adsorption of octyl hydroxamic acid/salt on cassiterite. Miner. Process. Extr. Metall. Rev. 2000, 20, 503-519.

2. Sreenivas, T.; Padmanabhan, N.P.H. Surface chemistry and flotation of cassiterite with alkyl hydroxamates. Coll. Surf. A Physicochem. Eng. Asp. 2002, 205, 47-59. [CrossRef]

3. Zhou, Y.C.; Tong, X.; Song, S.X.; Wang, X.; Deng, Z.G. Beneficiation of cassiterite fines from a tin tailing slime by froth flotation. Sep. Sci. Technol. 2014, 49, 458-463. [CrossRef]

4. Leistner, T.; Embrechts, M.; Leißner, T.; Chelgani, S.C.; Osbahr, I. A study of the reprocessing of fine and ultrafine cassiterite from gravity tailing residues by using various flotation techniques. Miner. Eng. 2016, 96, 94-98. [CrossRef]

5. Oliveira, J.F.; Adamian, R. Physico-chemical factors affecting the separation of cassiterite and fluorite by froth flotation. Miner. Process. Extr. Metall. Rev. 1992, 9, 125-134. [CrossRef]

6. Angadi, S.I.; Sreenivas, T.; Jeon, H.S.; Baek, S.H.; Mishra, B.K. A review of cassiterite beneficiation fundamentals and plant practices. Miner. Eng. 2015, 70, 178-200. [CrossRef]

7. Xu, Y.B.; Qin, W.Q. Surface analysis of cassiterite with sodium oleate in aqueous solution. Sep. Sci. Technol. 2012, 47, 502-506. [CrossRef]

8. Peng, H.Q.; Luo, W.; Wu, D.; Bie, X.X.; Shao, H.; Jiao, W.Y.; Liu, Y.K. Study on the effect of Fe ${ }^{3+}$ on zircon flotation separation from cassiterite using sodium oleate as collector. Minerals 2017, 7, 108. [CrossRef]

9. Senior, G.D.; Poling, G.W. The chemistry of cassiterite flotation. In Advances in Mineral Processing; Somasundaran, P., Ed.; SME Inc.: Littleton, CO, USA, 1986; pp. 229-254.

10. Collins, D.N.; Kirkup, L.; Davey, M.N.; Arthur, C. Flotation of cassiterite: Development of a flotation process. Trans. Inst. Min. Metall. 1968, 77, C1-C13.

11. Houot, R.; Desbrosses, Y. Is the cassiterite contained in complex sulfide polymetallic ore recoverable? Int. J. Miner. Process. 1991, 32, 45-57. [CrossRef]

12. Lepetic, V.M. Cassiterite flotation: A review. In Advances in Mineral Processing; Somasundaran, P., Ed.; SME Inc.: Littleton, CO, USA, 1987; pp. 343-350.

13. Zambrana, G.Z.; Medina, R.T.; Guierrez, G.B.; Vargas, R.R. Recovery of minus ten micron cassiterite by liquid-liquid extraction. Int. J. Miner. Process. 1974, 1, 335-345. [CrossRef]

14. Agarwal, Y.K. Hydroxamic acids and their metal complexes. Russ. Chem. Rev. 1979, 48, 948-963. [CrossRef]

15. Yale, Y.L. The hydroxamic acids. Chem. Rev. 1943, 33, 209-256. [CrossRef]

16. Bradshaw, D.J.; Harris, P.J.; O'Connor, C.T. Synergistic interactions between reagents in sulphide flotation. J. S. Afr. Inst. Min. Metall. 1998, 98, 189-193.

17. Bulatovic, S.; De Silvio, E. Process development for impurity removal from a tin gravity concentrate. Miner. Eng. 2000, 13, 871-879. [CrossRef]

18. Turanov, A.N.; Karandashev, V.K.; Yarkevich, A.N.; Safronova, Z.V.; Rodygina, N.I.; Fedoseev, A.M. Extraction of $\mathrm{u}(\mathrm{vi})$, th(iv), $\mathrm{pu}(\mathrm{iv})$, and am(iii) from nitric acid solutions with polyfunctional organophosphorus acids. Radiochimica 2007, 49, 618-623. [CrossRef]

19. Gruner, H.; Bilsing, U. Cassiterite flotation using styrene phosphonic acid to produce high-grade concentrates at high recoveries from finely disseminated ores-comparison with other collectors and discussion of effective circuit configurations. Miner. Eng. 1992, 5, 429-434. [CrossRef]

20. Wottgen, E. Adsorption of phosphonic acids on cassiterite. Trans. Inst. Min. Metall. Sec. C 1969, 78, 91-97.

21. Kuys, K.J.; Roberts, N.K. In situ investigation of the adsorption of styrene phosphonic acid on cassiterite by FTIR-ATR spectroscopy. Coll. Surf. 1987, 24, 1-17. [CrossRef]

22. Farrow, J.B.; Warren, L.J. Adsorption of short-chained organic acids on stannic oxide. Coll. Surf. 1988, 34, 255-269. [CrossRef] 
23. Tan, X.; He, F.Y.; Shang, Y.B.; Yin, W.Z. Flotation behavior and adsorption mechanism of (1-hydroxy-2-methyl-2-octenyl) phosphonic acid to cassiterite. Trans. Nonferrous Met. Soc. China 2016, 26, 2469-2478. [CrossRef]

24. Zhu, Y.M.; Luo, B.B.; Sun, C.Y.; Liu, J.; Sun, H.T. Density functional theory study of $\alpha$-Bromolauric acid adsorption on the $\alpha$-quartz (1 01 1) surface. Miner. Eng. 2016, 92, 72-77. [CrossRef]

25. Miller, J.D.; Wang, X.M.; Jin, J.Q.; Shrimali, K. Interfacial water structure and the wetting of mineral surfaces. Int. J. Miner. Process. 2016, 156, 62-68. [CrossRef]

26. Mulheran, P.A.; Harding, J.H. The stability of $\mathrm{SnO}_{2}$ surfaces. Model. Simul. Mater. Sci. Eng. 1992, 1, $39-43$. [CrossRef]

27. Mulheran, P.A.; Harding, J.H. Thermodynamic calculations of stannic oxide surfaces. J. Phys. IV 1993, 3, C7-1971-C7-1974. [CrossRef]

28. Oviedo, J.; Gillan, M.J. Energetics and structure of stoichiometric $\mathrm{SnO}_{2}$ surfaces studied by first-principles calculations. Surf. Sci. 2000, 463, 93-101. [CrossRef]

29. Slater, B.; Catlow, C.R.A.; Gay, D.H.; Williams, D.E.; Dusastre, V. Study of surface segregation of antimony on $\mathrm{SnO}_{2}$ surfaces by computer simulation techniques. J. Phys. Chem. B 1999, 103, 10644-10650. [CrossRef]

30. Bandura, A.V.; Sofo, J.O.; Kubicki, J.D. Derivation of force field parameters for $\mathrm{SnO}_{2}-\mathrm{H}_{2} \mathrm{O}$ surface systems from plane-wave density functional theory calculations. J. Phys. Chem. B 2006, 110, 8386-8397. [CrossRef] [PubMed]

31. Vlcek, L.; Zhang, Z.; Machesky, M.L.; Fenter, P.; Rosenqvist, J.; Wesolowski, D.J.; Anovitz, L.M.; Predota, M.; Cummings, P.T. Electric double layer at metal oxide surfaces: Static properties of the cassiterite-water interface. Langmuir 2007, 23, 4925-4937. [CrossRef] [PubMed]

32. Wu, Z.G.; Cohen, R.E. A more accurate generalized gradient approximation for solids. Phys. Rev. B 2006, 73, 235116. [CrossRef]

33. Rai, B.; Sathish, P.; Tanwar, J.; Pradip; Moon, K.S. A molecular dynamics study of the interaction of oleate and dodecylammonium chloride surfactants with complex aluminosilicate minerals. J. Coll. Interface Sci. 2011, 362, 510-516. [CrossRef] [PubMed]

34. Sahoo, H.; Sinha, N.; Rath, S.S.; Das, B. Ionic liquids as novel quartz collectors: Insights from experiments and theory. Chem. Eng. J. 2015, 273, 46-54. [CrossRef]

35. Li, F.X.; Zhong, H.; Zhao, G.; Wang, S.; Liu, G.Y. Flotation performances and adsorption mechanism of $\alpha$-hydroxyoctyl phosphinic acid to cassiterite. Appl. Surf. Sci. 2015, 353, 856-864. [CrossRef]

36. Feng, Q.C.; Zhao, W.J.; Wen, S.M.; Cao, Q.B. Activation mechanism of lead ions in cassiterite flotation with salicylhydroxamic acid as collector. Sep. Purif. Technol. 2017, 178, 193-199. [CrossRef]

37. Sauer, J.; Sustmann, R. Mechanistic aspects of Diels-Alder reactions: A critical survey. Angew. Chem. Int. Ed. Engl. 1980, 19, 779-807. [CrossRef]

38. Zhao, G.; Zhong, H.; Qiu, X.Y.; Wang, S.; Gao, Y.D.; Dai, Z.L.; Huang, J.P.; Liu, G.Y. The DFT study of cyclohexyl hydroxamic acid as a collector in scheelite flotation. Miner. Eng. 2013, 49, 54-60. [CrossRef]

39. Sun, L.H.; Li, G.P.; Chen, W.; Hu, J.F. Adsorption of $\mathrm{CO}$ on the oxygen defective $\mathrm{LaCoO}_{3}(001)$ surface: A first-principles study. Comp. Mater. Sci. 2016, 115, 154-157. [CrossRef]

(C) 2017 by the authors. Licensee MDPI, Basel, Switzerland. This article is an open access article distributed under the terms and conditions of the Creative Commons Attribution (CC BY) license (http://creativecommons.org/licenses/by/4.0/). 